\title{
Methodology for Integral Evaluation of Human Development Level as Exemplified by the Leading Countries of Asia-Pacific Region and European Union
}

\author{
Natalia Victorovna Kuznetsova ${ }^{1} \&$ Ekaterina Victorovna Kocheva $^{2}$ \\ ${ }^{1}$ Doctor of Economics, Professor, Department of World Economy, School of Economics and Management, Far \\ Eastern Federal University, Vladivostok, Russian Foundation \\ ${ }^{2} \mathrm{PhD}$, Assistant Professor, Department of Business Informatics and Mathematic Methods in Economics, School \\ of Economics and Management, Far Eastern Federal University, Vladivostok, Russian Foundation \\ Correspondence: Ekaterina Victorovna Kocheva, Suhanova Str., 8, Vladivostok, 690950, Russian Foundation. \\ E-mail: ipatovanat@mail.ru
}

Received: December 21, 2014 Accepted: March 20, 2015 Online Published: May 22, 2015

doi:10.5539/ass.v11n14p244 URL: http://dx.doi.org/10.5539/ass.v11n14p244

\begin{abstract}
The authors examine evolution of approach towards understanding of human capital and qualitative transformation of human's role in economics, conditioned by the transition to post-industrial society. Neo-classical approach has a special role in development of human capital theory. Examining human capital as a source economic growth of any country, the authors point out qualitative perfection of human potential. The article introduces methodology for integral evaluation of level of human development exemplified by the leading countries of Asia-Pacific Region an European Union. In addition, complex evaluation of human capital development is discussed as a two-side process: from one side, it is a formation of human abilities and skills, from the other side - realization of gained abilities and skills for the use of production or for recreation, cultural, political activity. Several key points of human development are pointed out for the purposes of a complex evaluation of human potential.

Authors' methodology of calculation of human development index is distinguishable from conventional methodology by at least one main principle: the authors believe that conducted experimental calculations might provide the most complete idea of human development from the point of view of three interconnected characteristics: human capital, human resources, and evaluation of conditions for formation and implementation of abilities and skills of a person.
\end{abstract}

Keywords: human capital, human potential, methodology, complex evaluation, Human Development Index, Asia-Pacific region, Human Potential Development Index, clusters, dendogram, social sectors

\section{Introduction}

In 60-80 years of the last century, there was a tendency to the emergence of the new economic growth theories (Lucas, Becker, \& Schultz) proving that the main factor of the economic growth was a human capital. The level of the society development is determined not only by the dominant types of economies, but also by the established hierarchy of values and interests, and the population characteristics, which is "human capital". The human capital involves the abilities, knowledge, and skills of employees, which give them the opportunity to operate in an economic environment. Investing in human capital tends to lead to higher productivity and increased production efficiency. A practice has shown that an increase in human capital through education, better health care and nutrition, affects economic growth, especially in the countries (regions) with low incomes and limited human capabilities.

A qualitative change in the role of man in the economy associated with the transition to a postindustrial society led to a growing interest in the problems of human capital and the reproduction of the human potential.

The main problem of the formation of sustainable development economics is still the efficiency of investing in human capital, which is now the central determinant of the level of the economic growth and the quality of life. 
The economy and the education level of the society are interdependent elements of the social system. Each of these elements influence the development of the other one in a very complicated way. If this relation is viewed from the perspective of the initial pulse, the priority, of course, belongs to the scientific and educational potential of society, because, in the conditions of information society, it acts as the most important factor in the reproduction of the national wealth and as an essential element of it. Considerable expenses for the development of education are not a consequence of the well-being of the country; it is an element of this prosperity.

There are many approaches to the definition of human capital as an economic category, as it is a very complex and multifaceted concept. Therefore, it could be claimed that this is a very ambiguous phenomenon which is also quite capacious and includes a lot of different areas such as social, economic, psychological, and even philosophical, as there is no aspect of human existence, which would, in principle, do not fall under the definition of a human capital. In the category of the human capital, it is necessary to see what is inherent in the capital as a whole notion, as well as particular properties that are specific for human capital. Hence, the existence of different definitions is quite natural, although it is obvious that the capital itself, as an economic phenomenon, is multifaceted, takes many forms, and performs different functions, i.e. becomes pervasive, "multifunctional".

\subsection{The Formation of the Human Capital Concept}

The paradigm of human capital was first formulated in 1960 by the future Nobel laureate American economist G. Becker. However, this concept did not appear out of nowhere, but was a natural result of the development of world economic thought. Its origins are seen in the works of the representatives of almost all schools of economics.

In the 17th century W. Petty, standing at the origins of classical political economy, put forward the idea of the primary values of labor skills in the national wealth of the country. A. Smith developed this idea, having included knowledge and qualification in the fixed capital of society, along with machines and land. He believed that the fixed capital consists of machines and other tools, buildings, land, and, "the acquired and useful abilities of all the inhabitants or members of the society."(Smith, 1956, p. 208). What is more, the last factor he put first, "the increase in productivity of useful work depends, first of all, on the increase of dexterity and the ability of the worker, and then on improvement of machines and tools with which he worked." (Smith, 1956, p. 235). Besides, A. Smith noted that these abilities, being a part of the characteristics of a particular person, at the same time become part of the wealth of the society to which the person belongs.

J. R. McCullosh clearly defined human resources as the capital (McCullosh, 1870, p. 57). In addition, he pointed out the close analogy between the common and human capital, considering that investment in human resources should have turnover rates consistent with the turnover rate of other investments plus the normal rate of turnover determined by the market interest rate during possible life of an individual. (McCullosh, 1870, p. 67). In our view, it was an attempt to quantify the human capital.

N. Senior suggested that human resources can be treated as capital; nonetheless, in this capacity, he took skills and acquired abilities, but not the person. (Senior 1939, pp. 68-69). On occasion, however, he treated human resources as capital with maintenance costs invested in person with the expectation of receiving benefits in the future. He argued that there is a slight difference between the arguments about the value of a slave and the values of a free man. The principal difference is that a free man sells himself for a certain period and for a certain relation, while the slave is sold on all his life.

H. Macleod considered the "producing" person as the fixed capital. From his point of view if this person isn't productive, he or she isn't subject to the economic analysis (Macleod, 1881, p. 134, 205-206, 213).

The Marginalists adhere to the following considerations about the nature of human capital. J. G. Von Thunen noted the reluctance of some economists to assess human resources in money, this reluctance, he said,"... arises the lack of clarity and confusion of concepts in one of the important areas of the political economy. Moreover, it may seem that the freedom and dignity of the people could be successfully provided, if they were subject to the laws of capital."(Thunen, 1875, p. 3). Von Thunen assumed that many social institutes could be cancelled if expenses which increase labor productivity, were considered in the analytical scheme of the human capital. The capitalized value of these expenses, besides, has to be included as a part in the aggregated stock of the capital (Thunen, 1875, pp. 1-10).

L. Walras included all human resources in the capital. And the value or the price of these human resources, Walras said, is defined like other capital goods (Walras, 1954, p. 40, 214-216). He argued that the pure theory, "inherent in complete abstraction from the consideration of fairness and practicality", and urged, "to consider human resources solely in terms of exchange value." (Walras, 1954, p. 271). 
At the beginning of the XX century, the neoclassic A. Marshall admitted that estimates of the capitalized cost of the person can be useful, and considered them in an explicit form by the method of capitalization of net earnings (consumption subtracted from earnings before capitalization) he rejected this notion as "unrealistic" because human resources are not sold on the market (Marshall, 1959, pp. 469-470, 705-706.).

The human resources were included in the definition of the capital by J. Fisher. Capital, as he claimed, is, "a useful intended material object", and, therefore, as human beings possess this characteristic, the sequence in reasonings demands their inclusion in the concept of the capital (Fisher, 1897, pp. 201-202; 1927, pp. 51-52, 68). However, the skill of an individual isn't the capital, it is an additive to the individual. J. Fisher pointed that there is trained individual who is to be included in the concept of capital (Fisher, 1965, pp. 12-13).

Thus, the question of whether or not the individual is a carrier of human capital has been resolved by the middle of the XX century. Though, there were different interpretations of the concept of human capital and controversy concerning the question whether the identity of the cost of useful skills and abilities and the cost of the individual.

From a variety of researches, it is decided to allocate a number of studies which reflect an attempt to mechanical projection of the concept of capital to human capital and attempt to evaluate it.

For example, E. Denison thought that talking about technological progress embodied in physical capital means simply to refer to changes in the quality of fixed assets (capital goods) (Denison, 1964, p. 91). Such an analogy could be applied to human resources as well. Skill and the acquired abilities are embodied in the person and, allegedly, increase their quality, as productive units. Therefore, their skill and abilities are integral from individuals, and the trained individual is the capital.

According to S. Huebner, the human capital can have the same scientific interpretation as the usual capital has. Its operational definition can be received "by capitalization of human life cost through bonds, giving them a life annuity (for this labor) and negotiability (as to a credit source), considering them by the principle of providing and using a method of depreciation funds for the implementation of the considered object, if only the person has prospect of future business activity, and his family has obligations to block the existing risk of uncertainty of duration of human life." (Huebner, 1914, pp.18-19).

Some authors used estimates of the capital cost of the person as an assessment of losses in World War I (Guyot, 1914; Crammond, 1915; Bogart, 1919). "The person is the capital," told I. Guyot, "and society have to be interested in the reduction of death not only on humanitarian, but also for the economic reasons." (Guyot 1914, p. 1197). E. Bogart claimed that the assessment of the monetary cost of the human lives lost in war is "method of doubtful statistical relevance", nevertheless, he considered that only the monetary assessment of these lives lost in war can help to realize their enormous economic importance. (Bogart, 1919, p. 269).

H. Boag considered a question of, whether it is correctly or not "to include in estimates of reduction of the capital, as costs of war, losses of human lives." (Boag, 1916, p. 7). He drew a conclusion that it is correct, as there is a close analogy between "material and human" the capital. Moreover, Boag has formulated some important issues relating to evaluation of the human capital. The first issue stated that the method of assessment should depend on the purposes for which the evaluation will be used. The second issue proposed that it is necessary to be careful in carrying out calculations for articles both for human, and for the usual capital. And, the third issue pointed that interference of costs of the usual and human capital should be taken into account.

H. Boag also noted that the method of capitalization of earnings in the evaluation of human capital has been more preferable since with the help of it the cost of material things is estimated, while the method of production cost may include an individual cost apart from its the effect on the increase in individual earning capacity. The "gross" method, in his view, is more preferable, because, “... in the calculation of material losses, losses of income are usually compared with the total national income, not the national savings, and, therefore, it is often better to consider the capitalized value of the gross income, but not the surplus income." (Boag, 1916, p. 11).

Although Nassau Senior previously noted that H. Boag was the first who accurately defined one of the difficulties connected with method of an assessment of the human capital at production cost; it is still precisely impossible to determine the amount of expenses for education and the contents is necessary for the production of the recipient of the income considered separately from his or her abilities "to love, enjoy, admire which cannot accompany the production of material wealth." (Boag, 1916, p.14).

J. Walsh noted, "Since the time of sir William Petty many economists included the person in the category of the fixed capital, because as like a capital the human demands spending for the creation and serves for the return of these expenses with a profit. This conclusion, nevertheless, is made in the general concepts, the relation is 
established for all people, as to the capital, and for all types of expenses on education and training, as its costs." (Walsh, 1935, p. 255).

S. Woods and J. Metzger showed that symmetry in consideration of both the human, and usual capital is reached only on condition of use of categories of "depreciation", "preservation", and "disposal". Preservation costs are recorded when the consumption costs are deducted from earnings, and depreciation with disposals are considered in the way in which average earnings are estimated, "this factor (depreciation and disposals) is entered into consideration by calculation of an average annual salary of workers, which includes a low wage of older workers along with a high salary of more effective producers. The former, of course, receives smaller salaries and wages than healthy and productive workers in the first half of their life, but the earnings of the latter are diluted with 'average' with lower earnings of the first group and those very young workers who have no qualifications yet" (Woods \& Metzger, 1927, p. 122).

As a result, these scientists draw a conclusion that the monetary cost of the population is the greatest asset of the country and that "the public citizens and students interested in national welfare actively support the progress promoting preservation of human life and the enjoyment of the available health, so that the productive life of individuals was extended and, therefore, added to the well-being of society." (Woods \& Metzger, 1927, p. 127).

This conclusion is contradicted by the opinions of some modern economists who claim that a further increase in costs of health care in the developed countries "will make health, but not welfare and, therefore, in an economic sense, it will be not quite productive" (Lees, 1962).

In the first quarter of the XX century there were a lot of works in which the authors used the analytical framework of human capital in an attempt to determine the monetary loss due to the prevention of disease and death (Fisher, 1908; Forsyth, 1914; Crum, 1919; Fisk, 1921). Their idea is to ensure that diseases and premature deaths lead to the loss of human capital and the effect of its accumulation can be increased by preventing and delaying diseases and deaths to the extent in which it is possible.

Thus, the analytical framework of human capital used by economists to explain it in the ordinary scheme of capital. In this context, it is necessary to pay attention to the problem of assessing and measuring the contribution of the intellectual potential of the individual and society as a whole in economic development.

The special attention to this question is deserved by K. Marx's views. K. Marx`s theory of reproduction of labor power is in line with the ideas of classical political economy. Marx, like classics, treated the person as fixed capital, emphasizing the great value in his or her development and accumulation of education, work experience, and expenses of free time.

From the social point of view, individual consumption is an integral part of social reproduction. K. Marx wrote, "Consumption is also a production just as consumption of chemical elements and substances is the production of a plant in the nature. That, for example, in the course of nutrition, representing one form of the consumption, with the help of which people make their own bodies; and it is quite clear, but it is also applicable to any other type of consumption, which, with one party or another, each in its own way, makes a man. This consumer production... is a second type of production, resulting from the destruction of the first one."(Marx, 1958, p. 719; 1969, p. 27).

He agreed that according to T. Hodgskin, abilities of the person to work are "the main accumulation of wealth, and most important preserved result of the previous work" (Marx, 1964, p. 306).

In the process of consumers' production, the individual labor is not only being produced, but also improved, and evolved. There is some kind of accumulation of productive force of work, creative abilities of the person, and more mental capacities.

Thus, the development of the labor force is able to create more value per unit of time than a simple one, i.e. has great use value, but as for its production consumes a large quantity of social labor, then it has a higher cost of reproduction. K. Marx wrote, "The work that has a meaning of higher and more complex work than the average social labor, is a manifestation of such a workforce, which formation requires higher costs, the production of which is worth more time, and, which, therefore, has a higher cost than simple labor. If the value of this force is higher, it manifests itself in a higher labor, and, therefore, materialized in equal intervals of time in the relatively higher cost "(Marx, 1960, pp. 208-209).

Thus, the cost of necessary social labor per unit of time and the quality of the workforce must match each other under equal conditions of application and the intensity of labor. According to this premise, all rates of hourly wages and salaries of employees, engineers and technical workers are set; for higher skilled workers, higher rates and salaries are set. 
The specific type of accumulation of the labor substantiated in the person remains rather low-investigated in economic science today. It is rather obvious that the physical development of man and his state of health depend on volumes and structure of food, the rationality of clothes, living conditions, services of health care; the intellectual development and professional qualifications of the person depend on volumes and structure of consumption, services of education, culture, and professional education. Processes of human personality development are studied by the representatives of different sciences, but still there is not a systemic nature that allows individual economists write that the costs of reproduction of labor, broadly defined as livelihood of the population, do not have a clear "technological" borders, but should be carried out regardless of participation in production.

K. Marx's allocation of necessary and additional labor as key concepts of his economic theory could be useful in the analysis of simple and expanded reproduction of labor for the certain person and the population in general. The category of labor cost is close, according to the contents, to the concept of reproduction of labor power costs. In the calculation of its value over the lifetime of the person it is close to the amount of lifetime costs for maintenance of human and investment in human capital. It is possible to say firmly that $\mathrm{K}$. Marx is one of considerable intellectual predecessors of modern developers of the neoclassical theory of the human capital.

Summarizing carried-out analysis of the genesis of the concept "human capital", we came to the decision that it is possible to conclude, that the concept "human capital", as separate economic category, is a result of natural development of economic science; and almost all representatives of all directions of economics, beginning with Petty and Smith, who considered various aspects of the concept, have contributed to the emergence of the concept.

As an independent branch of economic analysis, the theory of human capital was formed only at the turn of 50-60s of the 20th century. The merit of its promotion belongs to the famous American economist, the Nobel Prize laureate T. Schultz, and the basic theoretical model was developed by G. Becker (also the Nobel Prize laureate) in his book "The human capital" (the first edition of 1964). This book became the basis for all future research in this area and has been recognized as a classic of modern economics.

The development of human capital theory tended to follow the neoclassical direction. In recent decades, the source for the neoclassical principle of optimizing behavior of individuals began to spread to different areas of non-market activities of man. Concepts and methods of economic analysis have been used for the study of such social phenomena and institutions as education, health, migration, marriage and family, crime, racial discrimination, and so on. Human capital theory can be regarded as one of the manifestations of this general trend, dubbed "economic imperialism".

Thus, at this historic stage of the formation of human capital concept, it has been proven that "it (human capital) is a form of capital, because it is a source of future earnings or future satisfactions, or both together. It is human, because it is part of the person" (Bowen, 1978, p. 362).

The productive qualities and the characteristics of workers were found as a particular form of capital, on the grounds that their development requires a significant investment of time and material resources, and that it, like physical capital, provide its owner with higher incomes. "In recent decades, the idea that capital consists of some physical assets has been undermined. A more comprehensive view was gradually approved in its place. According to this view, the capital is any asset, the physical or human, possessing ability to generate a flow of future income" (Schutz, 1975, p. 5).

In the modern theory in a human factor three basic elements are allocated:

1) human capital, which corresponds to the return on the capital;

2) natural ability, which corresponds to the rents on these abilities;

3) pure work.

All the elements together characterize the work in the conventional sense, but the first two characterize human capital. It should be noted that the concept of human capital is not identical to the concept of the labor force, but human capital is capitalized labor costs.

Formation of physical capital and human capital formation have certain the technical and economic similarities. Both concepts require the diversion of significant funds at the expense of current consumption, the level of economic development in the future depends on these concepts, and both types of investments give long productive effect. 
Due to the theory of human capital, investment in human came to be regarded as a source of economic growth, not less important than the "normal" investments. T. Schutz, E. Denison, J. Kendrick and others made a quantitative assessment of the contribution of education to economic growth. It was found that during the 20th century, human capital accumulation outpaced the accumulation of physical capital. According to E. Denison's calculations, growth of per capita income in the United States during the postwar period was $15-30 \%$ due to a higher educational level of the workforce. An experience of such countries as Hong Kong, Singapore, South Korea confirms that the rate on investment into education and health care is the most effective strategy of economic development.

The kernel of the theory of the human capital is investment treatment of expenses for high-quality improvement of human potential (development of abilities and the formation of the requirements of the population), and also the characteristic of a contribution of these investments in economic growth.

D. Schutz substantiated the following thesis, "If education affects the production, which is important for the economy, therefore, it is a form of capital" (Schutz 1973, p. 50), and as "a form of capital is education, it is called 'human' because it becomes part of the person, and the capital is due to the fact that the future is a source of satisfaction or future earnings, or both together" (Schutz 1979, p. 13). G. Becker examined this concept in a broad sense, "Human capital is formed at the expense of investment in human, among which there are education, training in the workplace, health care costs, migration and search for information on prices and incomes" (Becker, 1962, p. 14).

Y. Ben-Porath defines human capital as the "fund, whose function is a production of labor services in conventional units, and which in its quality is similar to any car as the representative of the material capital" (Ben-Porath, 1967, p. 352). Edwin J. Dolan under the Human Capital understands "the capital in the form of intelligence obtained through formal training or education, or through practical experience" (Dolan 1992). S. Fischer, giving his definition of this category, relates to capital's ability to generate income, as well as innate abilities, education and the acquired qualification.

Summing up the results of our historiographic analysis, we can give the most complete definition to the category "human capital". Thus, human capital is a category representing set of the creative abilities, knowledge, skills, personal qualities and individual motivations which are on their property, accumulated due to investments and used in the national economy during the certain period for the purpose of obtaining future income and promoting growth of national wealth.

Increased knowledge of modern production capacity leads to a change in the concept of the economy in the development of labor to the opposite, highlights the creative potential of man, his professionalism and erudition, the ability to be "excessive", more than those roles and functions in which human could be replaced and appears only as "the next mortal carrier of the immortal social beginning". There is a formation of the new priorities of the personality and society, meaning the transition from maximizing material consumption to "quality of life": humanistic, ecological and in general to "not monetary" criteria of life.

\section{The Experimental Part}

In summary, we can say that the human capital and its conditions may be a criterion for evaluation of the quality and tends of processes which can be observed in the society. In this analysis the evaluation of the development of the human capital should be examined as a complex process. On the one hand, it is the formation of human capabilities (health protection, acquisition of knowledge, improvement of professional skills), and on the other hand - it is the realization of acquired skills for industrial purposes or for recreation, cultural and political activities. Thus, human development integrates the concept of "human capital" and "human resources".

As a criterion for evaluation of the development of the country and regions it can be used not only the economic indicators. During this research we refer to the experience of the global development of the countries which do not have natural resources and the countries with destroyed material base during the World War II (Taiwan, South Korea, Japan, and Germany). The strategy of socio-economic development of these countries was based on calculations per person. This strategy was a cause of high economic growth and high degree of its socialization.

The human development is often examined from the perspective of scientific and technological progress, the education and income component, which undoubtedly affects the healthy and safety life. However, nowadays there is a feeling of instability both in individual households and in the global socio-political system. Accordingly, the sustainable progress in the human development and the formation of human vitality depends not only on the empowerment of choice and the ability of receiving the education, being healthy, achieving a 
reasonable standard of living. It also depends on how reliable are these achievements and whether there are sufficient conditions for sustainable human development.

According to the modern trends it should be noted that in the global scientific literature there is a great number of ideas and concepts that aim to form the integral presentation of the individual which, on the one hand, could be worked out analytically and, therefore, be used strictly enough, and on the other hand, could be operated completely. However, nowadays there is no one equal definition of the category of the human development, and with this connection the question of the integral indicator is relevant.

\section{Methods}

For the complex evaluation of the human capital, it is necessary to allocate a few basic key areas of human development:

1. Development of the human capacity for knowledge, education, achieving of high qualifications, the development of science and innovation progress in society.

2. Adaptation of social programs for various categories of the population that will help to maximize the human potential and use it effectively in the economic and social development.

3. Formation and realization of human potentials in the existing socio-economic and political conditions.

The logic of formation the system of informative indicators for evaluation of the human capital is summarized to the following stages.

Firstly, for classification of statistical indicators, it was constructed the general scheme. Secondly, this general scheme is filled with concrete indicators which can help to evaluate the level of human potential.

The selection of indicators was carried out with the following requirements:

- representativeness, according to which it must be submitted in this list of the main indicators of this category;

- information availability, it means that the indicators should be available for its statistical registration, moreover, that it should be included in the range of official statistics;

- reliability, it means that the using statistics should adequately reflect the conditions of the analyzing aspects of human potential.

The analysis of the available information and the selected key areas of human development allowed us to form the priori selection of indicators. Selecting the number of members of a limited set of indicators was carried out in each case based on a combination of theoretical and substantive considerations.

During the next stage of analysis, in order to ensure the comparability of basic statistical information, each indicator, which is included in the integral index, is resulted to a common scale of measurement, i.e. normalized, and the particular choice of a unified transformation factor depends of the type of this analyzed indicator:

- if the initial indicator $x_{i}$ is connected with analyzed integral attribute (development of the human potential) by monotonically-increasing dependence (1):

$$
\widetilde{x}=\frac{x_{i}-x_{\min }}{x_{\max }-x_{\min }},
$$

where, $x_{\min }$ and $x_{\max }$ - the smallest and the largest values of the initial indicator.

- if the initial indicator $x_{i}$ is connected with the analyzed integral attribute by monotonically-decreasing dependence (2):

$$
\widetilde{x}=\frac{x_{\max }-x_{i}}{x_{\max }-x_{\min }},
$$

Thus, the linear transformations allowed us to reduce the range of possible values to the interval [0,1], and zero indicates the poor quality of this attribute, and one indicates the highest. 


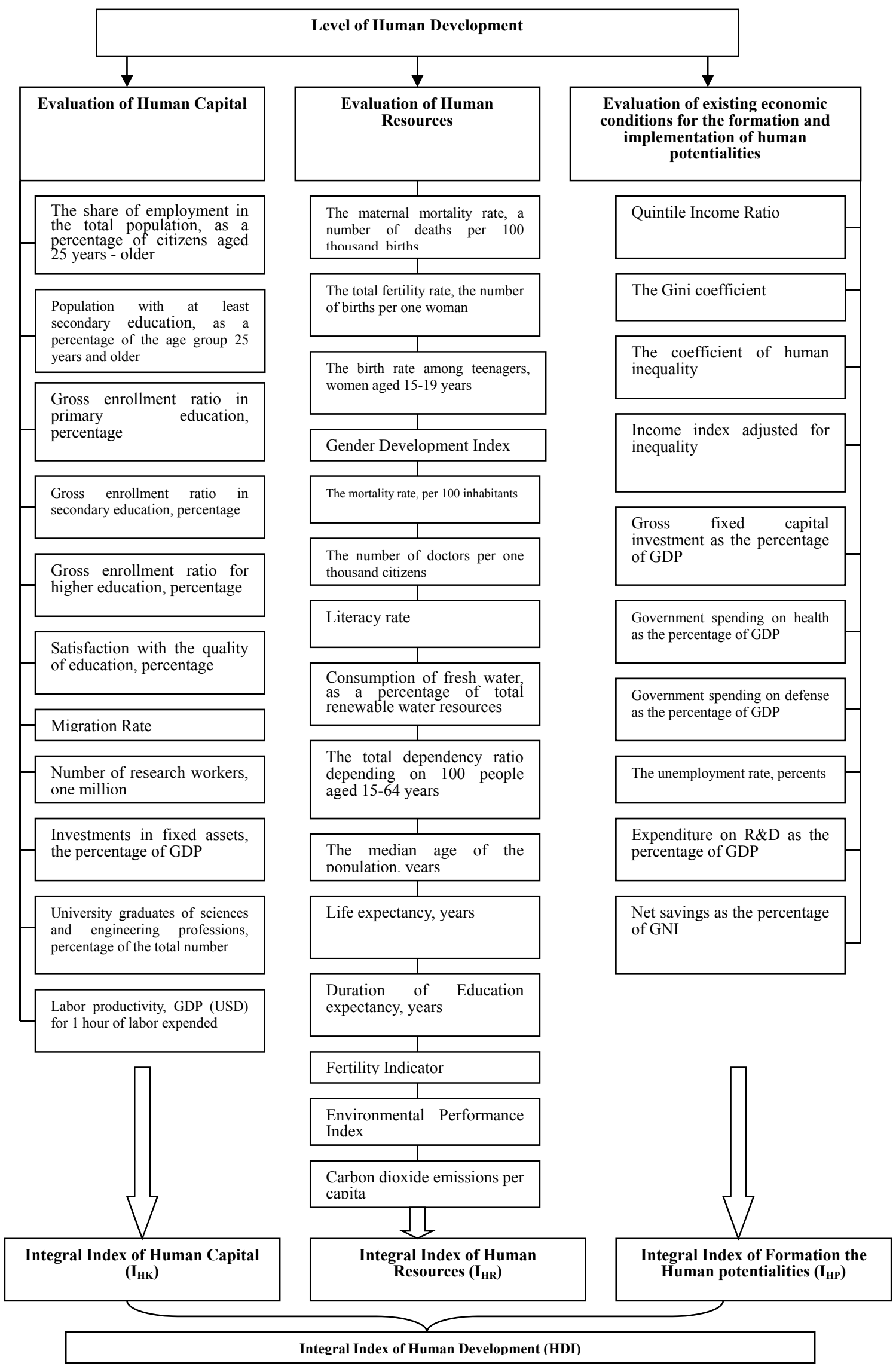

Figure 1. Methodology of the integrated evaluation of the level of human development 
During the next stage, we calculated the integral indicator for the each block of indicators (in vertical) (3).

$$
I_{i}=\sum_{i=1}^{n} w_{i} \widetilde{x}_{i}
$$

where, $I_{i}$ - integral index, which calculated for every block of indicators;

$w_{i}(i=1,2, \ldots \ldots, n)$ - weighting coefficient of $\mathrm{i}$-index in the integral index, which represents the proportion of explained variance characteristic in total variance;

$\tilde{x}_{i}$ - the normalized value of i-index which included in the corresponding block;

$n$ - the number of original normalized indicators included in the integral index.

Thus, as a result of transformations we obtain three integral indexes: IHK - Integral Index of Human Capital; IHR - Integral Index of Human Resources; IHP - Integral Index of formation of Human Potentialities.

As the integrated evaluation (horizontal) it is advisable to calculate the integral indicator of the human development in the aggregate determinants (Human Development Index (HDI)), which is a complex of evaluation of the partial criteria of this concept and it is designed for comparative analysis (in the categories of time and space).

In conclusion, integral index of human development HDI is calculated as the arithmetic mean of the integral indexes (human capital, human resources and potentialities of human formation) (4).

$$
H D I=\sum_{i=1}^{n} f_{i} I_{i}
$$

where, $f_{i}$ - the weight of corresponding integral indexes HDI: weight proportion of human capital is $1 / 3$, human resources $-1 / 3$, formation of human potentialities - $1 / 3 ; I_{i}$ - integral indexes: $\mathrm{I}_{\mathrm{HK}}-$ Integral Index of Human Capital; $I_{\mathrm{HR}}$ - Integral Index of Human Resources; $I_{\mathrm{HP}}$ - Integral Index of formation of Human Potentialities.

\section{Results}

Based on the above mentioned methodology it was calculated the integral characteristics of the largest countries in the Asia-Pacific Region and the EU. The results of calculations are presented below (Table 1).

Table 1. Integral indicators characterizing human development at the end of 2013

\begin{tabular}{cccccc}
\hline Country & $\mathrm{I}_{\mathrm{HK}}$ & $\mathrm{I}_{\mathrm{HR}}$ & $\mathrm{I}_{\mathrm{HP}}$ & HDI & Rang \\
\hline Australia & 0,669 & 0,718 & 0,517 & 0,634 & 4 \\
Great Britain & 0,576 & 0,698 & 0,451 & 0,575 & 9 \\
Germany & 0,661 & 0,703 & 0,555 & 0,640 & 3 \\
Hong Kong & 0,498 & 0,692 & 0,366 & 0,519 & 10 \\
India & 0,242 & 0,401 & 0,312 & 0,318 & 16 \\
Canada & 0,614 & 0,676 & 0,484 & 0,591 & 8 \\
China & 0,393 & 0,595 & 0,480 & 0,489 & 12 \\
Mexico & 0,320 & 0,672 & 0,324 & 0,439 & 14 \\
Mongolia & 0,428 & 0,642 & 0,373 & 0,481 & 13 \\
Norway & 0,720 & 0,750 & 0,457 & 0,642 & 2 \\
Republic of Korea & 0,638 & 0,666 & 0,586 & 0,630 & 5 \\
Russia & 0,491 & 0,684 & 0,365 & 0,514 & 11 \\
Singapore & 0,643 & 0,687 & 0,539 & 0,623 & 6 \\
USA & 0,668 & 0,684 & 0,577 & 0,643 & 1 \\
Thailand & 0,325 & 0,603 & 0,304 & 0,411 & 7 \\
Japan & 0,579 & 0,654 & 0,550 & 0,595 & 7 \\
\hline
\end{tabular}

Source: calculations of the authors

We made a comparison of the author's method for calculating the integral index of human development with the method suggested by Megnadom Desai (Lord Desai) and Amartya Sen. Human Development Index (HDI UN) was designed for comparing of the countries and was published in the annual UN report of Development Program since 1990. It was displayed the integral index of human development (HDI) and Human Development 
Index, calculated by the common method that published in the annual UN Report of Human Development (HDI UN) (Figure 2).

As we can see from Figure 2, during the comparison of two methods of calculating the human development index, it was not observed any sharp deviations in indicators of the countries which participating in this analysis. At the same time, the presented calculations indicate that the common patterns are preserved. The meaning of Human Development Index (HDI), which was calculated according to the author's method, takes the values lower than Human Development Index (HDI UN). It is connected with the fact that in the calculation process of Human Development Index (HDI) it is included simultaneously 37 indicators measuring human development from three areas: human capital, human resources and conditions for the formation and implementation of human potentials. It allows us to make fully and fairly accurately evaluation of the level of human development in order to create concepts and programs for socio-economic development of the country.

It was shown the distribution of the countries in terms of human development which presented the integral characteristics (Table 2). The leading positions in terms of human development are occupied by the USA, Norway, Germany, Australia and the Republic of Korea. These countries have all necessary conditions for the formation, development and implementation of human abilities.

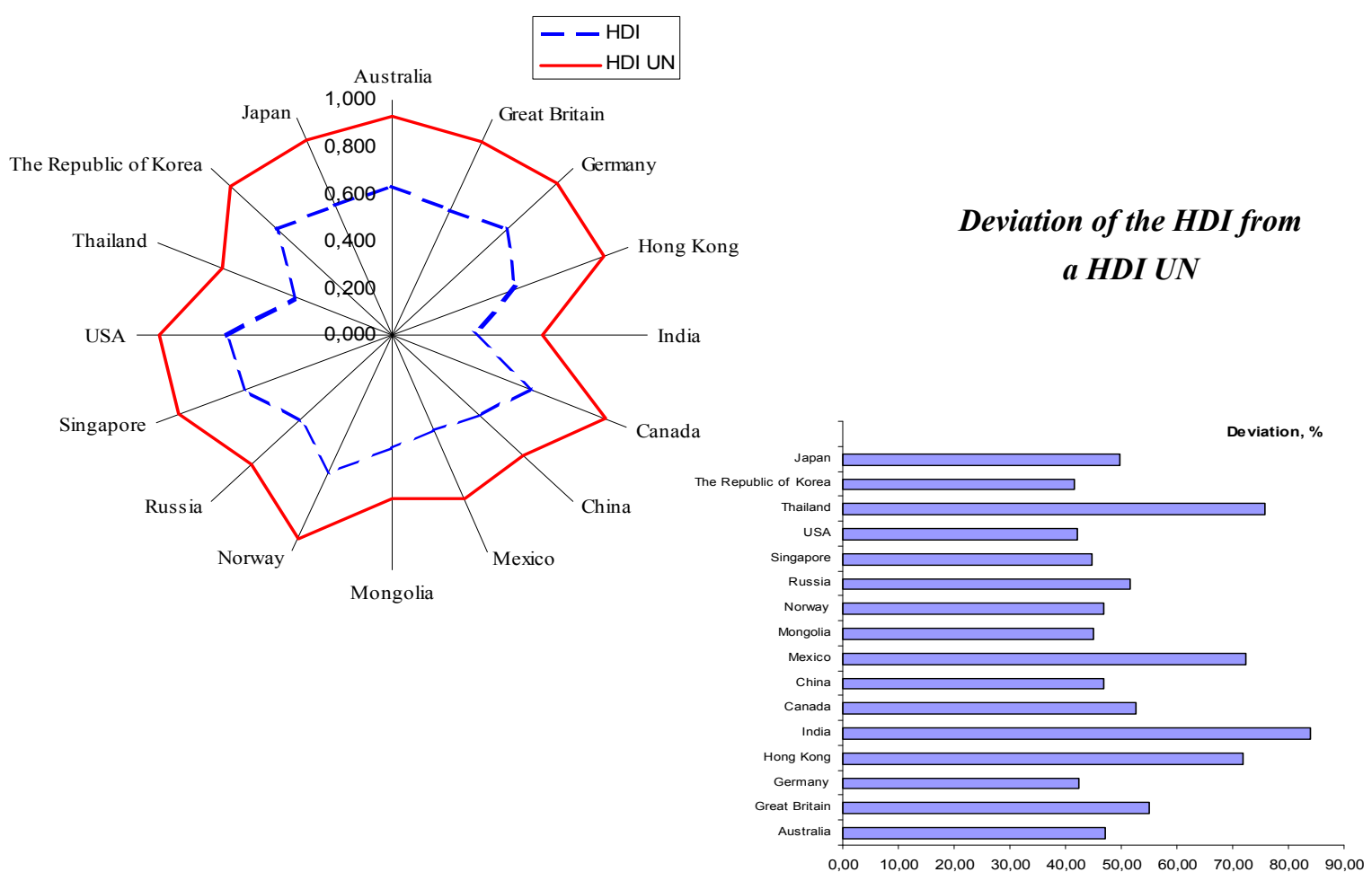

Source: calculations of the authors

Figure 2. Integral human development index, calculated by the author's method, and the human development index, calculated by the method of the United Nations, 2013

For comparison of two selections which obtained in the process of calculating of Human Development Index for classical method and author's method, we use nonparametric criteria. Firstly, we determined whether this distribution distinguish of normal. During our analysis we used the Kolmogorov-Smirnov test, and examined the distribution of the values of variables and HDI UN and HDI for the correspondents of the normal distribution (Table 2).

Thus, the line of Kolmogorov-Smirnov $\mathrm{Z}$ contains the $\mathrm{z}$-score, which is equal to the significance level for HDI 0,699 , for HDI UN 0,064 (last line). It means that the distribution of the value of the index HDI and the index HDI UN is not statistically different from normal.

In order to compare two indexes which measuring HDI UN, calculated according to the classical method of the $\mathrm{UN}$, and the integral index of HDI, calculated according to the author's method, we use Wilcoxon test. This 
criterion is based on calculation of the absolute differences between the pairs of values with subsequent ranking, and then the average value of calculated ranks for positive and negative differences (changes). The significance level is calculated on the basis of the standardized value. The result of applying Wilcoxon test is shown below (Table 3).

Table 2. One-Sample Kolmogorov-Smirnov Test

\begin{tabular}{llll}
\hline NPar Tests & & HDI & HDI UN \\
\hline $\mathrm{N}$ & & 16 & 16 \\
\hline Normal Parameters & Mean & 0,546 & 0,833 \\
& Std. Deviation & 0,098 & 0,107 \\
Most Extreme Differences & Absolute & 0,177 & 0,328 \\
& Positive & 0,163 & 0,149 \\
& Negative & $-0,177$ & $-0,328$ \\
Kolmogorov-Smirnov Z & & 0,707 & 1,312 \\
Asymp. Sig. (2-tailed) & & 0,699 & 0,064 \\
\hline
\end{tabular}

Source: calculations of the authors

Table 3. Two-Related Samples Wilcoxon Test

\begin{tabular}{cccc}
\hline Ranks & N & Mean Rank & Sum of Ranks \\
\hline Negative Ranks & 0 & 0 & 0 \\
(HDI UN $<$ HDI) & & & 136,00 \\
Positive Ranks & 16 & 8,50 & - \\
(HDI UN>HDI) & 0 & - & - \\
Ties (HDI UN=HDI) & 16 & - & - \\
Total & $-3,518$ & - & - \\
Test Statistics Z & 0,000 & - & \\
Asymp. Sig. (2-tailed)
\end{tabular}

Source: calculations of the authors

The visual analysis of the initial data suggests that the values of HDI UN exceed the value of HDI. It demonstrates the value of the criteria of test statistic which equal to $z=-3,518$, at a significance level of $p=$ 0,000 . It means that the difference between HDI and HDI UN recognized statistically significant.

During this analysis we reviewed the descriptive statistics for the characteristics of HDI UN and HDI (Table 4).

Table 4. Descriptive Statistics HDI UN, HDI

\begin{tabular}{ccc}
\hline Descriptive Statistics & HDI & HDI UN \\
\hline Minimum & 0,318 & 0,586 \\
Maximum & 0,643 & 0,944 \\
Mean & 0,546 & 0,833 \\
Std. deviation & 0,025 & 0,027 \\
S.E. Mean & 0,098 & 0,107 \\
Variance & 0,010 & 0,011 \\
Skewness & $-0,942$ & $-1,012$ \\
Kurtosis & 0,193 & $-0,011$ \\
K $_{\text {VAR }}$ & 5,46 & 7,94 \\
\hline
\end{tabular}

Source: calculations of the authors

These results of descriptive statistics indicated that the considered indexes are different from each other. We concluded that according to the more quality points for descriptive characteristics have HDI, which was calculated by the author's method, as indicated by the indicators of asymmetry, errors and coefficient of variation.

The main feature of the author's method for calculating Human Development Index (HDI) of the common technique (HDI UN) is that experimental calculations, according to the authors' opinion, can give a fairly complete view of the human development from the perspective of three interrelated characteristics: human 
capital, human resources and evaluation of the conditions for the formation and implementation of human abilities. The results of calculations according to the standard technique are overstated because of a limited set of indicators which used in the calculation of Human Development Index and, accordingly, it cannot completely appreciate all the positive and negative trends of the certain area.

For more detailed research of the human development of the researching countries, the authors considered to allocate the homogeneous groups of countries by the indicators included in each integral characteristic.

We distinguished some homogeneous clusters according to the indicators which characterizing the human capital. Based on this scheme, the authors implemented a multi-dimensional grouping of countries, which was carried out using the program SPSS Version 14.0 for hierarchical scheme by Ward's method, by the criterion of association, which is the metric of the city (City-block (Manhattan) distances) (Figure 3).

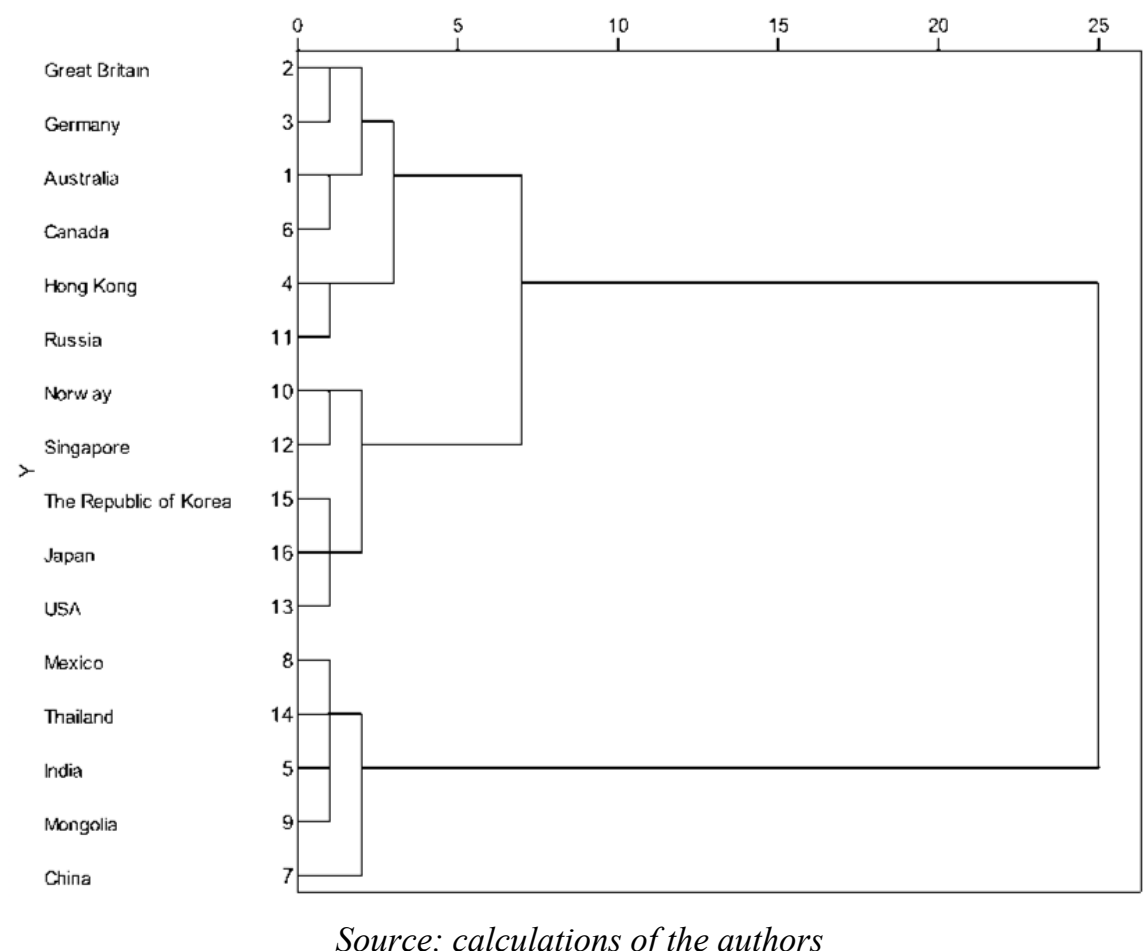

Figure 3. Dendogramma of countries' distribution according to the indicators characterizing the human capital

Thus, it was examined that the countries were divided as follows (Figure 3). The countries, such as the United Kingdom, Germany, Australia, Canada, Hong Kong and Russia, were included in the cluster $\mathrm{A}_{\mathrm{HK}}$. A special feature of this cluster is the fact that these countries have the population with secondary education. This group has the high rates of population with the secondary education. The interesting feature of this group is that it has the largest share of college graduates of science and engineering specialties.

The cluster $\mathrm{B}_{\mathrm{HK}}$ included Norway, Singapore, South Korea and the United States. This group in conditions of human capital differs from the others that it is focused more qualified staff. The countries of this cluster are dominated by people with higher education. The number of researchers is mainly due to Norway, Japan and Singapore, the number of researchers is the largest in the cluster. Notable, that in this group there is a migration growth in these countries, which also affects the level of labor productivity.

The cluster $\mathrm{C}_{\mathrm{HK}}$ included Mexico, Thailand, India, Mongolia and China. These countries have the highest proportion of the employed population. It was recorded the highest coverage of primary education. A feature of this cluster is the largest amount of investment in capital assets, mainly it is China and Mongolia.

With the usage of the authors' methodology it was implemented the grouping of countries according to the indicators describing the development of human resources (Figure 4).

In the cluster $\mathrm{A}_{\mathrm{HR}}$ it was included Germany, Japan, Australia, Canada, Norway and the United Kingdom (Figure 4). A feature of this cluster is the high level of literacy. This group of countries has the highest life expectancy, which is about 81, however, it was also marked the highest mortality rates (except Australia). In this case, the 
number of doctors per 1000 of citizens in this group is predominant in comparison with other clusters. It is observed that this cluster has the most senior population, the median age is 41 . As a consequence, the countries of this group have the high demographic pressure on the working-age population. If we say about the indicators of environmental sustainability, it is observed the highest carbon dioxide emissions, but it is noted the favorable trend of the index of environmental achievements.

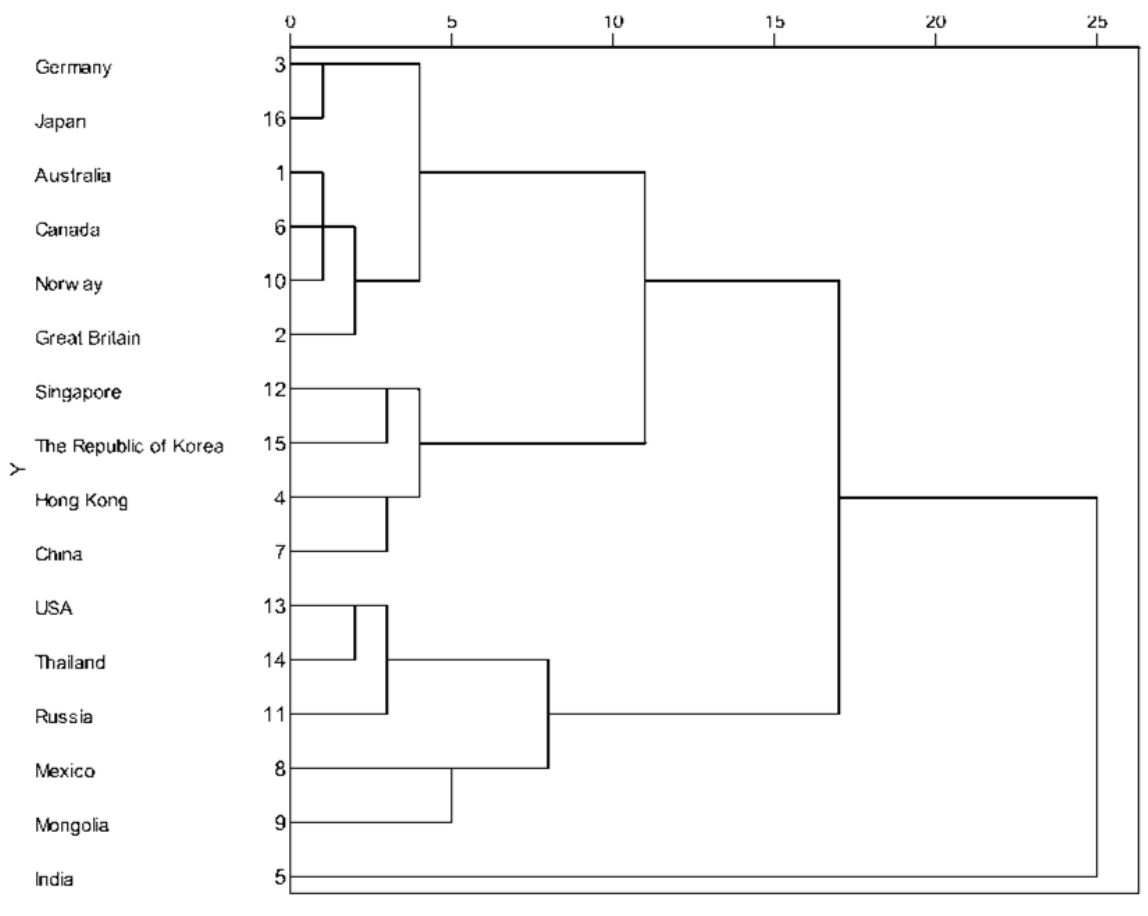

Source: calculations of the authors

Figure 4. Dendogramma of countries' distribution according to the indicators characterizing the human recourses

In the cluster group $\mathrm{B}_{\mathrm{HR}}$ it was included Singapore, South Korea, Hong Kong and China. This cluster is different from the others by the points that it is marked by low values of mortality. However, despite of the positive trend of the low level of mortality in this group it was the low values of the coefficient of birth rates and fertility rates. In the countries of the cluster $B_{\mathrm{HR}}$, it was marked the low rates of demographic burden on the working population. A feature of this cluster is the fact that there has the highest consumption of fresh water (as a percentage of total renewable water resources).

The cluster $\mathrm{C}_{\mathrm{HR}}$ included the United States, Thailand, Russia, Mexico, Mongolia and India. This cluster has the high values of fertility. However, despite of the favorable trend in this cluster it was marked the high levels of mortality, including maternal, mainly in Mexico, Mongolia and India. The level of literacy in this group is at a low level in comparison of the previous cluster. It was examined that in this group has a young population, its average age is 31 .

The grouping of countries according to the indicators characterizing the conditions for the formation and realization of human potentials was presented below (Figure 5).

As we can see from Figure 5, the countries can be divided into two enlarged clusters.

The cluster $\mathrm{A}_{\mathrm{HP}}$ included Australia, Canada, United Kingdom, Hong Kong, Russia, the USA, Germany, Japan and Norway. A feature of this cluster is the high value of the index of income, adjusted for inequality. This group of countries is dominated by government spending on health, education and science, in comparison with a cluster of $\mathrm{B}_{\mathrm{HP}}$.

The cluster of $\mathrm{B}_{\mathrm{HP}}$ included China, Mongolia, Mexico, Thailand, India, the Republic of Korea and Singapore. These countries in this group are characterized by high differentiation of the population by income, mainly in Thailand, Mexico, India and China. In this cluster, there are high volumes of fixed capital (the largest share of China and Mongolia), as well as high net savings, mainly in China and Singapore. 

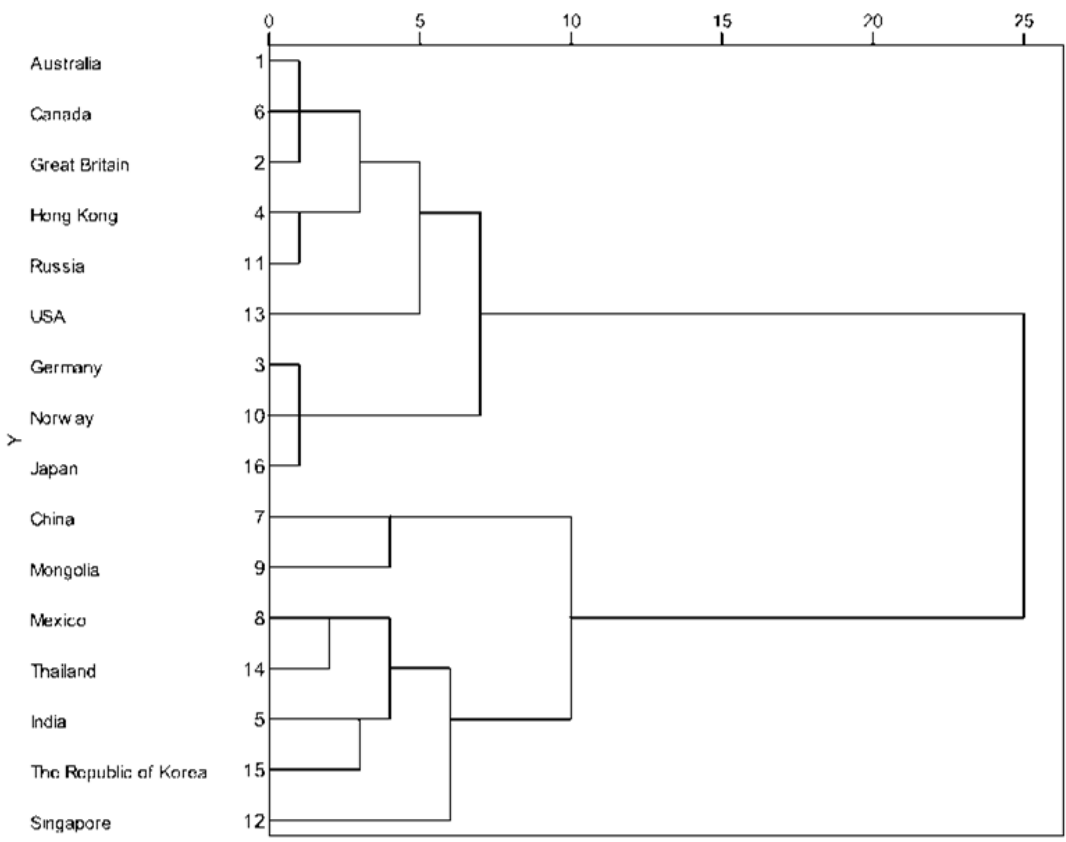

Source: calculations of the authors

Figure 5. Dendogramma of countries' distribution according to the indicators characterizing the economic conditions for formation and realization of human potentials

\section{Conclusions}

Thus, we can make the following conclusions. The experimental evaluations of the level of human development according to the author's method due to the construction of integral characteristics accumulates indicators of human capital, human resources and indicators to assess the conditions of formation of human potentials, given a complete picture of human development in terms of cross-country comparisons. Thus, the present research of human development gave us the opportunity for more qualitatively understanding of the category of human development as the main wealth of the country, as well as generates some approaches to the definition of administrative decisions in social and economic policy.

The problem of human development should be formulated as a fundamental task of modernizing the state complex of social sectors: education, health, culture and science. Firstly, the social programs and projects should be directed at improving the starting opportunities of citizens, and besides the area of residence; the formation of modern human infrastructure, i.e. human potential to be a part of the modern processes. The results of socio-economic development of the country, and the level and quality of life depend of the main cause of how to use and develop the human potential in the country.

Thus, the presented technique of this research examined the dynamics of socio-economic systems, causing the level of human development, it allows us to develop strategies and social development programs aimed at human development, its potential as the major wealth of the state, allocate resources to strategically important priorities in the field of human development of the country.

\section{Acknowledgment}

The results were achieved within the frameworks of the governmental assignment of Russian Ministry of Education and Science in the sphere of scientific research during the researching assignment \# 26.1478.2014/K "The structural transformation of Russian Economy through the integration installation in the industrial markets of Asia-Pacific Region”

\section{References}

Becker, G. S. (1962). Investment in Human Capital: A Theoretical analysis. Journal of Political Economy, 70(5), 9-49.

Ben-Porath, Y. (1967, August). The Production of Human Capital and the Life Cycle of Earnings. The Journal of Political Economy, 75(4), Part 1. Published by: The University of Chicago Press. 
Boag, H. (1916). Human Capital and the Cost of War. Royal Statis.Soc.

Bogart, E. L. (1919). Direct and Indirect Costs of the Great World War. New York: Oxford Univ. Press.

Bowen, H. R. (1978). Investment in Learning. San Francisco.

Crammond, E. (1915, May). The Cost of War. J.Royal Statis. Soc.,LXXVIII.

Crum, F.S. (1919). Public Accidents and Their Cost. Proc.Nat.Safety Council. Eighth Annual Safety Congress.

Denison, E. F. (1964, March). The Unimportance of the Embodied Question. A.E.R., LIV.

Dolan, E. G., \& Lindsey, D. E.(1992). Microeconomics. Saint-Petersburg: Copyright Publishing.

Fisher, I. (1897). Senses of Capital. Econ. J., VII.

Fisher, I. (1908). Cost of Tuberculosis in the United States and its Reduction. Read before the International Congress on Tuberculosis, Washington.

Fisher, I. (1927). The Nature of Capital and Income. London: Macmillan \& Co.

Fisher, I. (1965). The Theory of Interest. New York: Augustus M. Kelley.

Fisk, E. L. (1921). Health of Industrial Workers. Waste in Industry. Washington; Federated American Engineering Societies.

Forsyth, C. H. (1914-15). Vital and Monetary Losses in the United States Due to Preventable Deaths. American States. Assoc. Publication, XIV.

Guyot, I. M. (1914, December). The Waste of War and the Trade of Tomorrow. Neinteenth Century and After.

Huebner, S. S. (1914, July). The Human Value in Business Compared with the Property Value. Proc. Thirty-fifth Ann.Convention Nat. Assoc.Life Underwriters.

Lees, D. S. (1962). An Economist Considers Other Alternatives. Financing Medical Care ed. Hemut Shoeck. Caldwell, Idaho: Caxton Priners Ltd.

Macleod, H. D. (1881). The Elements of Economics (Vol.11). New York: D.Appleton@Co.

Marshall, A. (1959). Principles of Economics. New York: Macmillan Co.

Marx, K., \& Engels, F. (1958). Economic Manuscripts 1857-1858 (2nd ed., V. 12).

Marx, K., \& Engels, F. (1960). Capital, Volume 1: the Process of Production of Capital (2nd ed., V. 23).

Marx, K., \& Engels, F. (1964). Manuscript, Proletarian Enemies of Political-Economics Coming from Ricardian Economic Theory (2nd ed., V. 26/3).

Marx, K., \& Engels, F. (1969). Economic Manuscripts 1857-1859 (2nd ed., V. 46/1).

McCullox, J. R. (1870). The Principles of Political Economy. Alex Murrey @ Son.

Schutz, D. W. (1975). Human Capital: Policy Issues and Research Opportunities. Human Resources. Fifteen Anniversary Colloguium V1. N.Y.

Senior, N. W. (1939). An Outline of the Science of Political Economy. New York: Farrar @ Rincart.

Shultz, D. (1979). Scientific productivity. The effectiveness of research groups in six countries. Cambridge.

Shultz, D. (1973). The coming of Post-Industrial Society. N.Y.

Smith, A. (1956). An Inquiry into the Nature and Causes of the Wealth of Nations. M.: Socecgiz.

Thunen, H. I. (1875). Der isolierte Stadt (Vol. 11, Part 11). Translated by Bert F. Hoselitz. Chicago: Corporative Education Center, Univ. of Chicago.

Walras, L. (1954). Elements of Pure Economics. Translated by William Jaffe. Homewood,Ill.:Rickard D.Irwin.

Walsh, J. R. (1935, February). Capital Concept Applied to Man. Q.J.E., XLIX.

Woods, E. A., \& Metzger, C. B. (1927). Americas Human Wealth: Money Value of Human Life. New York: F.S. Crofts@Co.

\section{Copyrights}

Copyright for this article is retained by the author(s), with first publication rights granted to the journal.

This is an open-access article distributed under the terms and conditions of the Creative Commons Attribution license (http://creativecommons.org/licenses/by/3.0/). 